\section{Individualized strategic planning for faculty development in medical schools}

\author{
Goutham Rao, ${ }^{1}$ Steven L. Kanter, ${ }^{2}$ \\ Ora A. Weisz, ${ }^{2}$ Ann Thompson, ${ }^{2}$ \\ Theresa Ratti, ${ }^{2}$ Jennifer Woodward ${ }^{2}$
}

1University of Chicago Pritzker School of

Medicine, North Shore University Health

System, IL; ${ }^{2}$ University of Pittsburgh

School of Medicine, PA, USA

\section{Abstract}

Background. Faculty development is essential to provide skills not taught in typical medical training such as designing curricula or scientific writing, to help medical faculty acquire new skills valued today such as financial management, and to maintain institutional vitality. Faculty development receives relatively little attention in many medical schools and is narrowly focused upon teaching skills.

Innovation. We propose a program that includes individual needs assessment and strategic planning. This strategy is consistent with Knowles' principles of andragogy, a model of adult learning that differs in some ways from traditional pedagogy. We have included a selfassessment tool that may be useful to medical schools and an illustrative case study.

Evaluation. We have introduced the selfassessment tool to a small number of faculty members who have found it clear and useful. We plan to introduce it to a large number of faculty members and to measure completion rates, perceived usefulness, and subsequent participation in faculty development activities and fulfillment of goals.

Conclusions. Faculty development needs to be a higher priority in medical schools and to better reflect the current needs of faculty members. An individualized faculty development process has the potential to have a substantial impact upon acquisition of important skills, and faculty and institutional morale and vitality.

\section{Background}

Faculty development can be defined as $a$ process by which faculty members achieve excellence in teaching, scholarship, and service. ${ }^{1}$ It encompasses a broad range of skills including teaching, scientific writing, presentation skills, financial management, career management, and research skills. Faculty development is an essential part of the activities of medical schools. First, and most obvi- ously, the skills encompassed by faculty development are seldom taught in medical schools or residency programs. Second, faculty roles and responsibilities today are more demanding and diverse than in the past. The third compelling reason for faculty development is that it is essential for institutional morale and vitality. Half of all faculty members are over the age of $55 .^{2}$ Interest in academic careers is declining among graduating medical students and residents. ${ }^{3}$ This is not surprising given the overwhelming evidence that discontent with academic medical careers is widespread. In a recent survey, $42 \%$ of medical school faculty members reported that they were seriously considering leaving academic medicine in the next five years. ${ }^{4}$ A survey published in 2003 revealed that $71 \%$ of primary care faculty members who had left faculty positions believed it was unlikely or very unlikely that they would ever return to academic medicine. ${ }^{5}$ The reasons for such widespread discontent are diverse and include the perceived poor quality of life for faculty members, a lack of recognition for teaching in many medical schools, a lack of opportunities to participate in decisions which affect all faculty members, and a lack of opportunities for faculty development. ${ }^{6}$ Turnover of faculty members in medical schools is very high and replacing faculty members is very expensive. Well planned faculty development programs that respond directly to faculty members' needs have been shown to improve satisfaction and retention. ${ }^{6,7}$ Furthermore, the most powerful predictor of productivity for an individual faculty member is his or her institutional environment. ${ }^{8}$ Faculty development is an important resource to support productivity.

\section{Current status of faculty development}

Despite its importance, faculty development receives relatively little attention in medical schools. A survey of 76 medical schools conducted in 2000 revealed that faculty development was the responsibility of a variety of different departments and offices including offices of faculty or academic affairs. ${ }^{9}$ Only 15 of the schools had an office dedicated to faculty development.

In addition to receiving relatively little attention in medical schools, we are concerned that current faculty development activities are too narrowly focused on teaching skills. Steinert has pointed out the need to broaden the scope of faculty development to encompass leadership, management and other areas..$^{10} \mathrm{~A}$ review of published reports of faculty development activities by Skeff et al. revealed an overwhelming emphasis on teaching skills, including teaching specific curricular topics. In fact, in their paper, improving teaching and faculty development are synonymous. ${ }^{11}$
Correspondence: Goutham Rao, Department of Family Medicine, University of Chicago, Pritzker School of Medicine, Center for Clinical and Research Informatics, North Shore University, Health System, 1001 University Place, Suite \#138, Evanston, IL 60201, USA.

Tel. +1.847.6441851 - Fax: +1.224.364.7319

E-mail: grao@northshore.org

Key words: faculty development, medical education, strategic planning.

Conflict of interests: the authors declare no potential conflict of interests.

Received for publication: 8 January 2013. Accepted for publication: 8 January 2013.

This work is licensed under a Creative Commons Attribution NonCommercial 3.0 License (CC BYNC 3.0).

(C) Copyright G. Rao et al., 2013

Licensee PAGEPress srl, Italy

Medical Education Development 2013; 3:e2

doi:10.4081/med.2012.e2

\section{Innovation}

What follows is a description of a systematic approach to faculty development that involves self-assessment of faculty development needs, followed by discussion and negotiation of a plan that best addresses those needs as well as the needs of departments and institutions. While faculty development has a generally low profile in many medical schools and is often narrowly focused, most institutions can provide opportunities to fulfill faculty development needs by steering faculty members to appropriate mentors, courses, or other activities. The idea is not to develop a large number of new faculty development programs designed for everyone, but to make use of existing resources to meet individual needs. The strategy of individualized strategic planning is grounded in adult learning theory, and follows Knowles' seven principles of andragogy (Table 1). ${ }^{12}$ What follows is a case-study that illustrates the individualized strategic planning process. We have also developed a self-assessment tool based on the principles of andragogy that is included in the case.

\section{Case study: introduction}

Charles Matz is a thirty-two-year-old physician. He completed his residency in family medicine two years ago in a community hospital, where he served as chief resident. He worked as a hospitalist during his first year of 
Table 1. Seven principles of andragogy and individualized faculty development planning.

\section{Principle}

Establish an effective, safe learning climate.

Involve learners in mutual planning and curricular content.

Involve learners in diagnosing their own needs - this will help trigger internal motivation.

Encourage learners to formulate their own learning objectives. Encourage learners to identify resources and identify strategies for using the resources to achieve objectives.

Support learners in carrying out their learning plans.

Involve learners in evaluating their own learning - this can help develop their skills of critical self-reflection.

\section{Relationship to individualized faculty development planning}

Faculty members begin by completing a self-assessment of their own needs based on careful self-reflection. They are provided ample time and support to do this. Faculty members are the primary drivers of faculty development planning. They design a curriculum or plan that they believe best meets their own needs.

Self-assessment is clearly consistent with this principle.

Self-assessment of needs is accompanied by setting of goals by faculty members. This activity also accompanies the self-assessment.

Departmental and institutional support is essential, and is discussed and negotiated as part of the faculty development plan.

Faculty members are expected to provide an update on progress in their faculty development plan annually. New plans are to be developed every two years.

Table 2. Faculty development self-assessment tool. Instructions: This self-assessment is intended to identify the knowledge and skills you either need to acquire for the first time or knowledge and skills you need to review or practice in order to fulfill your professional goals. It is not intended as a self-assessment of your performance. Complete the form by describing your faculty development needs (if any) in each domain. Your Division Chief or Chair will review your completed form after which you and he/she can negotiate a formal faculty development plan that takes into consideration both your needs and the needs of your division or department.

\section{What are your faculty development goals in each of the following areas for the coming year?}

Clinical

Research/scholarly activity

Teaching

Academic administration/leadership

Professional self-development

Personal self-development Through

Clinical

Research/scholarly activity

None

Would like to learn how to design a small, health-services research study None

Interested eventually in assuming an administrative leadership role, and would like to learn about conflict resolution Would like to better understand the process of promotion and granting of tenure

Would like some help with time management

Teaching

Academic administration/leadership

Professional self-development

Personal self-development

Would like to take a research course, and work with an experienced mentor to design a study

How much time do you believe you will need to fulfill your faculty development needs in each area?

Clinical

Research/scholarly activity

3 hours per week

Teaching

Academic administration/leadership

2 hours per week

Professional self-development

2 hours per month

Personal self-development Unsure

What additional resources do you believe will be needed to fulfill your faculty development needs in each area (e.g. funding, mentorship)?

Clinical

Research/scholarly activity

An experienced mentor

Teaching

Academic administration/leadership None

Professional self-development None

Personal self-development Unsure

In what ways can your Department Chair/Division Chief assist you in meeting your goals in each domain?

Clinical

Research/scholarly activity

Recommend an experienced mentor

Teaching

Academic administration/leadership

Discuss her own experience with conflict resolution

Professional self-development

Personal self-development

Discuss her own perspectives on promotion and tenure

Unsure 
Table 3. Summary of objectives/activities for faculty development plan.

Negotiated activities/objectives

\section{Research}

1. To complete basic research skills course.

2. Regular meetings (roughly monthly) with research mentor.

Academic administration/leadership

3. Two separate meetings with Dr. Harper to discuss her experiences with conflict resolution.

4. Two meetings with 2 other physician leaders to discuss conflict resolution.

\section{Professional self-development}

5. Dr. Matz is encouraged to attend seminars on promotion and tenure and his clinical schedule will be adjusted accordingly.

6. To read two useful books on time management for professionals.

7. To meet with a university career counselor on at least one occasion to discuss time and stress management.

practice. Having always had an interest in academic medicine, Dr. Matz then joined the faculty of the department of family medicine of a well respected allopathic medical school. The department was badly in need of clinicians due to increasing patient demand, and his position involves $75 \%$ of Dr. Matz's time spent in direct clinical care with $25 \%$ somewhat ambiguously allocated for teaching, research, and other activities. Overall, Dr. Matz is very satisfied with his work environment. He gets along well with his colleagues and enjoys his interactions with students and residents. His department is very active in clinical research, and a number of his colleagues are leading large research projects, some of which are funded by the National Institutes of Health. Dr. Matz has no background in research (apart from a summer spent in a chemistry lab in college), but has an interest in improving the quality of life of patients with heart failure. He has attended a number of research seminars and conferences on this topic. He has made it clear to his chair, Dr. Harper, on several occasions, that he would be interested in pursuing research in this area. She, in turn, has expressed her support, but both she and Dr. Matz are unsure about how to move toward this goal.

Dr. Matz completes a self-assessment tool shown in abbreviated form in Table 2 , which includes five broad domains of faculty development. Table 3 summarizes the objectives/activities negotiated as part of Dr. Matz's faculty development plan.

\section{Case study: conclusion}

Dr. Harper reviews Dr. Matz's completed form, and the pair sits down to discuss options. She is happy to support his research interest and allocates time both for a research skills' course and time with an experienced mentor whom she knows very well. She encourages him to attend seminars on promotion and tenure which are offered regularly. Dr. Matz identifies a course in the business school on conflict resolution, but Dr. Harper feels its timing would disrupt his clinical activities and those of the department too much. Instead, she offers to discuss her own experiences with conflict resolution, and refers Dr. Matz to other physician leaders for the same purpose. Dr. Harper reveals that she herself struggles with time management and setting priorities. She recommends a couple of books she has found useful, and a University counselor who specializes in stress and time management. Dr. Matz is grateful for Dr. Harper's help. She, in turn, feels she has learned a great deal about his career interests. Dr. Harper makes it clear to Dr. Matz that he is expected to provide a brief written update next year that describes the extent to which he has met his faculty development goals.

The approach described in the case study has distinct advantages. Dr. Matz's faculty development plan is based on his own needs and availability of resources. In many institutions, faculty development activities are developed and offered without taking individual faculty members' needs into account. Completion of the self-assessment form promotes strategic thinking about faculty development, an exercise Dr. Matz would not have otherwise completed. It also allows his chair to better understand his interests and priorities.

\section{Evaluation}

We have introduced the faculty development self-assessment tool to twelve faculty members at the University of Pittsburgh and the University of Chicago. Though we have not yet formally evaluated its impact, the tool was perceived to be easy to understand and useful in stimulating thinking about faculty development and identifying specific needs. Our next step will be to introduce the tool more systematically and broadly to a large number of learners. We will incorporate the tool into an electronic portfolio system being developed at the University of Chicago Pritzker School of Medicine. Our evaluation will include basic process measures including completion rates, but also formal evaluation of the perceived evaluation of the tool among faculty members and department chairs. Finally, we recommend that the tool be completed every two years. We will therefore be able to measure the extent to which faculty members have met their faculty development goals as well as the engagement (e.g. in workshops) of faculty members in faculty development activities in general.

\section{Conclusions}

Faculty development should be a higher priority for medical schools and evolve to meet the needs of medical faculty today. Most current faculty development programs emphasize teaching skills. Individual strategic planning involves self-assessment of and reflection about faculty development needs. This is followed by discussion and negotiation of a plan that best meets faculty members' and departmental needs, and which can be carried out with available resources.

\section{References}

1. Rose EA, Roth LM, Werner PT, et al. Using faculty development to solve a problem of evaluation and management coding: a case study. Acad Med 2000;75:331-6. 
2. Bland CJ, Bergquist WH. The Vitality of senior faculty members: snow on the roof Fire in the furnace. ASHE-ERIC Higher Education Report. Washington DC: The George Washington University Graduate School of Education and Human Development; 1997. pp 25.

3. Bickel J, Brown AJ. Generation X: Implications for faculty recruitment and development in academic health centers. Acad Med 2001;80:205-10.

4. Lowenstein SR, Fernandez G, Crane LA. Medical school faculty discontent: prevalence and predictors of intent to leave academic careers. BMC Medical Education
2007;7:1-8.

5. Anderson WA, Grayson M, Newton D, Zoeller ED. Why do faculty leave academic medicine? J Gen Intern Med 2003;18 Suppl $1: 99$.

6. Bland CJ, Seaquist E, Pacala JT, et al. One school's strategy to assess and improve the vitality of its faculty. Acad Med 2002;77:368-76.

7. Wingard DL, Garman KA, Reznik V. Facilitating faculty success: outcomes and cost benefit of the UCSD National Center of Leadership in Academic Medicine. Acad Med 2004;79:S9-11.

8. Clark SM, Lewis DRE. Faculty vitality and institutional productivity: critical perspectives for higher education. New York: Teachers College Press; 1985.

9. Morahan PS, Gold JS, Bickel J. Status of faculty affairs and faculty development offices in U.S. medical schools. Acad Med 2002;77:398-401.

10. Steinert Y. Faculty development in the new millennium: key challenges and future directions. Med Teach 2000;22:44-50.

11. Skeff KM, Stratos GA, Mount JFS. Faculty development in medicine: a field in evolution. Teaching Teach Educ 2007;23:280-5.

12. Kaufman DL. Applying educational theory in practice. BMJ 2003;326:213-6. 